\title{
Mikulicz's disease and Sjögren's syndrome as the main autoimmune disorders involving salivary glands
}

\section{Choroba Mikulicza i zespół Sjögrena jako główne choroby autoimmunologiczne zajmujące gruczoły ślinowe}

\author{
Bartłomiej Kamiński \\ Otolaryngology Ward, Maria Sklodowska-Curie District Hospital, Skarżysko-Kamienna, Poland \\ Head of the Ward: Bartłomiej Kamiński MD, PhD
}

Key words: Mikulicz's disease, Sjögren's syndrome, IgG4-related diseases.

Słowa kluczowe: choroba Mikulicza, zespół Sjögrena, , choroba zależna od IgG4.

\begin{abstract}
Mikulicz's disease and Sjögren's syndrome involve salivary glands. They are characterised by lymphocytic infiltrations in affected exocrine glands leading to their swelling and dysfunction. Although they present similar clinical symptoms, currently they belong to different classifications and require different multidisciplinary treatments. This study presents and compares Sjögren's syndrome and Mikulicz's disease and reviews their main clinical, histopathological, and serologic criteria and the methods used in the diagnostic process. The most reliable diagnostic method is histopathologic examination of glandular tissue obtained by either minor or major salivary gland biopsies. Serologic criteria play an additional diagnostic role. The different radiological modalities allow the exclusion of other inflammatory and neoplastic processes that can mimic the initial stages of Mikulicz's disease and Sjögren's syndrome.
\end{abstract}

\section{Streszczenie}

Choroba Mikulicza i zespół Sjögrena zajmują gruczoły ślinowe. Charakteryzują się naciekami limfocytarnymi w zajętych gruczołach zewnątrzwydzielniczych, co prowadzi do ich obrzęku i dysfunkcji. Chociaż oba te schorzenia cechuje podobny obraz kliniczny, obecnie są odmiennie klasyfikowane i wymagają innego leczenia wielospecjalistycznego. W artykule przedstawiono chorobę Mikulicza oraz zespół Sjögrena i porównano je ze sobą. Omówiono ich główne kryteria kliniczne, histopatologiczne i serologiczne, a także metody stosowane w diagnostyce. Badanie histopatologiczne tkanki gruczołowej pobranej z małych lub dużych gruczołów ślinowych jest najpewniejszą metodą diagnostyczną. Badania serologiczne odgrywają dodatkową rolę. Różne metody radiologiczne pozwalają na wykluczenie procesów nowotworowych i zapalnych, które w początkowych fazach choroby mogą naśladować zespół Sjögrena i chorobę Mikulicza.

\section{Introduction}

Mikulicz's disease (MD) and Sjögren's syndrome (SS) are the main autoimmune disorders involving salivary glands. They induce a characteristic histopathological pattern of affected salivary glands termed as sialadenitis. Although they are usually limited to exocrine glands, they can affect many organs. They are systemic, chronic inflammatory processes and require a multidisciplinary approach. They are characterised by lymphocytic infiltration of the salivary and lacrimal glands and recurrent or persistent enlargement of salivary glands leading to gland dysfunction. In the past, MD was considered as a subtype of SS. According to a new classification approved by the European League Against Rheumatism (EULAR) in 2018, MD belongs to immunoglobulin G4 (IgG4)related diseases (IgG4-RD). Both entities, MD and SS, present similar histological and clinical symptoms. This can lead to misdiagnosis and the implementation of inappropriate therapy. Moreover, incorrect terminology and classification of both diseases from the past result in many pitfalls and discrepancies in their diagnosis and treatment [1-4]. The aim of this study was to present and compare SS and MD and to review their main clinical, histopathological, and serologic criteria and the methods used in the diagnostic process of these diseases with respect to their differentiative value. 


\section{Epidemiological pattern and clinical presentation}

Sjogren's syndrome is an autoimmune disease involving exocrine glands. The mean age of onset in SS is estimated to be $45-55$ years [5]. Contrary to SS, MD typically occurs in middle-aged or elderly men. The median age of the onset of IgG4-RD is 58 years [6]. Although systemic presentation of IgG4-RD reveals a predilection to male gender with the ratio estimated at 2.8-3.5: 1, MD and other IgG4-RD in the head and neck area demonstrate an almost $1: 1$ ratio [3]. According to Rolla et al., the male-female ratio is approximately $5: 1$ [6]. Gender predilection is estimated differently depending on the lesion location. Sialadenitis and dacryoadenitis typically to MD are more common in women than in men [7]. SS indicates a predilection to female gender with female/male ratio $9: 1$ [5]. It is the first demographic difference between $\mathrm{MD}$ and SS. The main symptoms in MD develop for many months. SS usually presents with shorter history. The first signs in both entities may mimic infections or chronic inflammatory process. Episodes of high, spiking fever and weight loss can occur in the subclinical period. Moreover, generalised weakness, malaise, and fatigue may precede the main disease development. Arthralgia, arthritis, or severe ocular dryness or xerostomia can be the first sign in SS. $30-40 \%$ of patients with MD present a longstanding history of allergic conditions. IgG4-RD is characterised by the formation of pseudotumourous lesions in single or multiple organs. MD involves mainly major salivary glands and lacrimal glands, and it is characterised by submandibular, parotid gland, and lacrimal gland enlargement, infiltration, and formation of pseudotumours. Lymphadenopathy of the head and neck is a frequent accompanying symptom of MD [3]. Onset of MD can be asymptomatic. In the active stage of the disease the main patient complaints depend on the mechanical compression exerted by the fibrotic masses in salivary glands. The enlargement of lacrimal and salivary glands in MD is elastic, painless, bilateral, symmetrical, and persistent and maintains for more than 3 months [1]. In contrast, the lacrimal and salivary swelling in SS occurs repeatedly and disappears without treatment [1]. It is not a predominant symptom and should be differentiated from lymphoma accompanying SS. The involvement of exocrine glands in SS is usually associated with extraglandular manifestations. SS may occur as primary or secondary form. Primary SS occurs in the absence of another rheumatic disease, whereas secondary SS is related to another autoimmune disease [3]. Both entities are characterised by multiorgan involvement and require multidisciplinary and comprehensive diagnosis and treatment. They present systemic manifestation. SS can exist with other autoimmune diseases. Arthralgia or arthritis occur in about 30\% of SS sufferers. Renal involvement of SS includes interstitial nephritis leading to renal tubular acidosis and membranous glomerulonephritis. Significant renal diseases develop in $5 \%$ of SS patients, and the subclinical renal features of disease are observed in $30 \%$ of SS patients [5]. The interstitial infiltrates of lymphocytes around the bronchioles cause interstitial pneumonitis in approximately $25 \%$ of patients with SS. Neurological manifestation as a multiple sclerosis-like syndrome is estimated at $1 \%$. Raynaud's phenomenon is a common vasculopathy reported in SS. The most severe complication of SS is the development of B-cell lymphoma. Primary SS is characterised by a 44 -fold increased risk of mucosa-associated lymphoid tissue (MALT) type B cell lymphoma [5]. The complications of MD are autoimmune pancreatitis (AIP), retroperitoneal fibrosis, tubulointerstitial nephritis, autoimmune hypophysitis, and Riedel's thyroiditis. It is not clear that these conditions are the direct consequence of MD or other manifestation of IgG4-RD [7, 8]. The main lesion locations in IgG4-RD include pancreas, bile ducts, lungs, aorta, retroperitoneal space, lymph nodes, lacrimal glands, and orbit and oculomotor muscles. The head and neck location is the second most common site after the pancreas $[5,7]$. The occurrence of IgG4-RD in the head and neck area is estimated at 20\% [9]. Some previous studies revealed the high possibility of cancer in this group of patients. This risk is estimated at $7 \%$ of patients with IgG4-RD and may occur 5 years after the onset of the disease [7]. Serological findings indicate a reciprocal relationship between MD and other IgG4-RD and allergic entities, including allergic rhinitis, nasal polyps, bronchial asthma, and atopic dermatitis [7]. One of the most differentiative features between MD and SS is a response to glucocorticoids. Mikulicz's disease is characterised by a good response to steroid therapy. Most of the patients show rapid improvement after this therapy. Glucocorticoids cause a reduction of the infiltration mass in salivary glands and a decrease of serum IgG4 concentration. The disease can recur when steroids are reduced or withdrawn. Glucocorticoids should be implemented in patients with active lymphoplasmatic infiltrations in histopathological examination. An initial dose of prednisone should be maintained for 2-4 weeks and gradually reduced for 3-6 months. Surgery is recommended in cases of severe and predominant fibrosis of salivary glands and poor response to pharmacological therapy. Thorough observation without rapid initiation of therapy may be considered in moderate lymphadenopathy and a moderate enlargement of salivary glands. Contrary to SS, antirheumatic drugs in the MD therapy can be treated as an adjunctive treatment [10]. In SS immunosuppressive drugs play a predominant role in the treatment. Glucocorticosteroids are combined with other immunosuppressive drugs. Steroids are implemented in the case of intensification of organ changes, vasculitis, and nervous sys- 
tem involvement [11]. Serologic and histopathological examinations play a crucial role in the diagnosis. Histopathological examination is useful to exclude neoplastic or inflammatory conditions that can present similar symptoms. The current diagnostic criteria for MD and SS are presented in Table 1.

\section{Xerostomia and xerophthalmia in differentiative diagnosis of SS and MD}

Most individuals with SS present with xerophthalmia and/or xerostomia. These are the predominant symptoms of SS and are among the diagnostic criteria. In previous SS classifications, both objective and subjective oral and ocular dryness tests were included in diagnosis of SS. The current classification is based only on an objective clinical test, which is presented in Table 1. Sicca symptoms in SS are a consequence of chronic exocrinopathy. SS starts with the epithelial inflammation termed as autoimmune epithelitis and impaired function of the exocrine glands manifesting in the reduction of saliva or tear secretion. The secretory function is impaired through the reduction of secretion of the aqueous phase and changes in density of the secretion [11]. The lack of symptoms of dryness confirmed by objective tests in patients with MD is the main differentiative factor between SS and MD. The coincidence of dry eye disease and SS is estimated to be $46.7 \%$. The main consequences of ocular dryness include conjunctival hyperaemia and corneal epithelial damage leading to functional vision impairment. Squamous metaplasia of the ocular surface epithelium, follicular conjunctivitis, corneal epitheliopathy, recurrent erosion, and corneal ulceration were also described in SS [11]. The rate of dry mouth in SS ranged from $41 \%$ at initial diagnosis to $84 \%$ 10 years after diagnosis [12]. According to SS classification criteria, an unstimulated salivary flow rate of $0.1 \mathrm{ml} / \mathrm{min}$ in sialometry gives a score of 1 to the weighted sum of five items. The lack of saliva in the mouth causes higher risk of oral candidosis, caries, and opportunistic infections. The oral cavity without the antibacterial properties of saliva is predisposed to oral mucosal lesions [13]. SS-related xerostomia can correspond with selected inflammatory and diagnostic factors of the disease severity and with histopathological changes in salivary glands [14]. There is a negative correlation between disease duration and increasing rate of saliva secretion. It does not respond to steroid or immunosuppressive therapy. These therapies only soothe symptoms of xerostomia or xeropthalmia but do not improve saliva and tear secretion. Therefore, current management of xerostomia and xerophthalmia includes application of tear and saliva substitutes and sialagogues such as pilocarpine and cevimeline and parasympathomimetics [5]. Xerostomia is more severe in primary SS than in secondary SS. Other exocrine glands may be affected, too. Dry skin and dry hair are accompanying symptoms in SS [15]. About $30 \%$ of patients have diminished vaginal secretions. A lack of mucus secretion in the gastrointestinal tract leads to reflux oesophagitis or gastritis

Table 1. Comparison of diagnostic criteria for IgG4-RD and SS approved by EULAR

\begin{tabular}{|c|c|c|}
\hline Diagnostic criteria & IgG4-RD (and MD) & SS \\
\hline Clinical symptoms & $\begin{array}{l}\text { 1. Enlargement or abnormal functions } \\
\text { of affected organ/s }\end{array}$ & Not included in diagnosis \\
\hline Serological criterium & $\begin{array}{l}\text { 2. Increased serum IgG4 concentration } \\
\geq 135 \mathrm{mg} / \mathrm{dl}\end{array}$ & Anti-SSA/Ro positivity (3 points) \\
\hline $\begin{array}{l}\text { Histopathological } \\
\text { examination }\end{array}$ & $\begin{array}{l}\text { 3. Characteristic changes in histopathological } \\
\text { examination: } \\
\text { - infiltration composed of lymphocytes and } \\
\text { plasmatic cells and fibrosis } \\
\text { - infiltration of lgG4+ cells }>10 \text { cells lgG4+ } \\
\text { hpf in a high-resolution microscope and } \\
\text { quantitative ratio of lgG4+/lgG }>40 \%\end{array}$ & $\begin{array}{l}\text { Labial salivary gland biopsy (focal } \\
\text { lymphocytic sialadenitis FSL) with Focus } \\
\text { Score FS } \geq 1 \text { (3 points) }\end{array}$ \\
\hline Xerostomia & Not treated as a criterium & $\begin{array}{l}\text { Unstimulated salivary flow } \leq 0.1 \mathrm{ml} / \mathrm{min} \\
\text { (1 point) }\end{array}$ \\
\hline Xerophthalmia & Not treated as a criterium & $\begin{array}{l}\text { Schirmer's test } \leq 5 \mathrm{~mm} / 5 \mathrm{~min} \text { ( } 1 \text { point) or } \\
\text { Ocular Staining Score (OSS) } \geq 5 \text { or van } \\
\text { Bijsterveld score } \geq 4 \text { ( } 1 \text { point) }\end{array}$ \\
\hline $\begin{array}{l}\text { Comprehensive } \\
\text { diagnosis }\end{array}$ & $\begin{array}{c}\text { Certain diagnosis: meeting the requirements } \\
\text { of } 1,2,3 \\
\text { Probable diagnosis: meeting the } \\
\text { requirements of } 1 \text { and } 3 \\
\text { Possible diagnosis: meeting the requirements } \\
\text { of } 1 \text { and } 2\end{array}$ & $\begin{array}{l}\text { Diagnosis } \geq 4 \text { points } \\
\text { A total score of } 4 \text { for the above items } \\
\text { meeting the criteria for primary SS }\end{array}$ \\
\hline
\end{tabular}


[5]. Xerostomia is not a constant symptom in MD and usually is less severe than in SS. Its occurrence is estimated in $30 \%$ of patients. Moreover, it is usually sensitive to immunosuppressive and steroid therapy. Therefore, the objective tests with measurement of saliva or tear secretion are excluded from the diagnostic criteria of all IgG4-RD and MD.

\section{Serological findings}

The main serological finding in MD is increased level of serum IgG4. According to diagnostic criteria, it should have a minimum value of $135 \mathrm{mg} / \mathrm{dl}$. The probability of this diagnosis is significantly increased when this level is higher than $270 \mathrm{mg} / \mathrm{dl}$ [7]. Furthermore, IgG4 serum concentration correlates with decreased salivation and fibrotic changes in glandular tissue. IgG4 concentration in serum can be used as a useful marker for monitoring the efficacy of treatment [5]. Although it is one of the diagnostic criteria for all IgG4$\mathrm{RD}$, it is not largely specific. Its production can be a response to interleukin 6 and 10 level [7]. Increased serum IgG4 levels can be associated with other conditions and can mimic infections, malignancies, and other connective tissue disorders. An increased serum IgG4 level is observed in $2 \%$ of patients with cancer [7]. Many autoimmune diseases such as lupus erythematosus and rheumatoid arthritis are characterised also by the increased level of serum IgG4. Furthermore, high serum IgG4 level occurs only in $60-70 \%$ of patients with MD [4]. The increased IgG4 level is a result of B-lymphocyte activity and inappropriate activation of T lymphocytes. The IgG4-related symptoms are a response to Th2-dependent cytokines. Serum IgG4 level exhibits sensitivity ranging from $82.3 \%$ to $89.3 \%$ and a specificity of $94.6 \%$ to $95.8 \%$ [16]. Its positive predictive value in diagnosing ranges from 36\% to $79 \%$ [16]. Moreover, this predictive value does not correspond with the cut-off value of the IgG4 level [17]. Therefore, it should be regarded only as a useful screening tool, especially if the probability of the disease is low and IgG4 immunostaining of an involved salivary gland is nondiagnostic or not available $[4,17]$. In SS the serum IgG4 level is normal or increased to a lesser extent, especially in secondary SS, and it could be treated as an important differentiative factor from IgG4-RD. Except the higher total concentration of serum IgG4 in MD, the ratio of serum IgG4 to total IgG is significantly elevated in IgG4-RD [17]. Other immunoglobulins, including IgM, IgA, and other IgG subclasses, can be elevated in MD but usually not to the extent of IgG4 [4]. There are no changes in serum immunoglobulin levels in SS. MD sufferers present increased serum IgE level. In one third of patients with IgG4-RD, eosinophilia is observed [7]. Moreover, this elevated level significantly correlates with IgG4 concentrations. Eosinophilia and increased serum $\operatorname{IgE}$ level are reported more frequently in IgG4-related lacrimal gland enlargement and overlapping asthma-like symptoms. These findings can be explained by the enhanced Th2 cell differentiation and IL-10 production in the pathogenesis of IgG4-related lacrimal gland enlargement [16]. Thrombocytopenia rarely occurs in MD in contrast to SS [18]. MD patients exhibit normogammaglobulinaemia or hypergammaglobulinaemia and normocomplementaemia or hypocomplementaemia [1]. The important differentiative factors between SS and MD are immunologic markers observed in rheumatic diseases. In MD antinuclear antibodies (ANA), ANCA antibodies or decreased components C3 and $\mathrm{C} 4$ are not detected [7]. On the other hand, these immunologic markers are treated as diagnostic criteria in SS. A positive serum anti-Ro/SSA or/and anti-La/SSB typically to SS is an important diagnostic criterium. The exocrine glandular epithelium is a main source of these autoantigens. According to ACR and Sjögren's

Table 2. Main epidemiological, clinical, serologic, and histopathological differences between MD and SS

\begin{tabular}{|lcc|}
\hline Parameter & MD & SS \\
Gender ratio male/female & $2.5: 1$ & $1: 9$ \\
Gland swelling & Persistent & Recurrent \\
Xerostomia & None or slight & Mild or severe \\
Keratoconjunctivitis sicca & None or slight & Mild or severe \\
Response to steroid therapy & Good & No changes or good \\
Serum IgG & Normal-very high & Normal-high \\
Serum IgG4 level & Increased & Normal \\
Antinuclear antibodies & Dominance of negative cases & Dominance of positive cases \\
Anti-SSA/SSB antibodies & Negative & Positive (70\%/30\%) \\
Gland biopsy & Infiltration of abundant lgG4-positive plasmacytes & No detection of lgG4-positive cells \\
\hline
\end{tabular}


International Collaborative Clinical Alliance (SICCA), positive rheumatoid factor $(\mathrm{RF})$ and $\mathrm{ANA} \geq 1: 320$ are an equivalent to anti-SSA/SSB positivity, but they are not approved criteria by EULAR [11] (Table 2).

\section{Histopathological criteria of SS and MD}

Histopathological examination plays an important role in the diagnosis of both entities. It is considered a reliable diagnostic test. Lymphocytic infiltrations found in affected salivary glands give pantognomic histological pattern termed as sialadenitis. These histopathological findings are specific for all salivary glands. However, the glandular tissue specimens for microscopic examination are harvested by labial salivary gland biopsy (LSGB). The microscopic confirmation of SS is based on the presence of focal lymphocytic sialadenitis (FLS) with a focus score (FS) $\geq 1$ per $4 \mathrm{~mm}^{2}$ of glandular tissue. LSGB is considered positive if the examination reveals FLS, with a focus score of 1 or more. A lymphocytic focus is termed as a dense aggregate of 50 or more lymphocytes adjacent to normal-appearing mucous acini [19-22]. FLS has to be distinguished from acinar atrophy, interstitial fibrosis, and ductal dilatation, and lymphocytes, which are scattered in the parenchyma but do not form aggregates. There are two alternative scoring systems of salivary glands used for SS diagnosis. Grading according to Tarpley's system involves destruction of acinar tissue and fibrosis [23]. Grading according to the Chisholm and Mason system is based on the description of infiltrates [24]. The sensitivity of these histopathological changes in LSG biopsy ranges from $63.5 \%$ to $93.7 \%$ and specificity from $61.2 \%$ to $100 \%$. However, in $18-40 \%$ of the SS patients LSGB is negative [25]. Although the detection of FLS in LSGB is a reliable diagnostic criterium, $6-9 \%$ of the healthy individuals have FS $>1$ in LSG and $5 \%$ in the parotid gland biopsy. FLS should be differentiated from nonspecific chronic sialadenitis (NSCS), sclerosing chronic sialadenitis (SCS), granulomatous inflammation, infiltrates within normal limits, marginal zone (MALT) lymphoma, and germinal centre [26]. The new insight in SS diagnostics is the histopathological examination of parotid glands. In the current recommendation other histopathological features in the salivary glands that are associated with SS might be indicative of this disease. Lymphoepithelial lesions (LELs) are striated ducts, which are infiltrated by lymphocytes with concurrent hyperplasia of the epithelial cells. Severity of the LELs can be classified into three stages: stage 1 - a partial LEL (affecting $<50 \%$ of the epithelium); stage 2-developed LELs (affecting 50-100\% of the epithelium); and stage 3 - occluded LELs (affected epithelium without lumen). These histopathological diagnostic features are more representative and useful in parotid glands than labial glands. Besides LELs, the salivary gland of SS patients also presents a relative decrease in IgA+ plasma cells. A relative decrease of
$<70 \%$ IgA+ plasma cells is more specific and more sensitive than the FS, especially when the FS in the biopsy is $<1$. An evaluation of the salivary gland biopsy for the presence of LELs and $<70 \%$ IgA+ plasma cells besides the FS may aid in the correct diagnosis of SS. Histopathological examination in SS is based on the number of foci and does not include the size of these foci and the real amount of glandular tissue involvement. This is especially important in the case of a single and confluent focus. The possible changes in the foci size can be more useful for evaluation of treatment effects and disease progression. For the better detection of the area of infiltrate, the immunohistological staining for CD45 is recommended additionally to regular haematoxylin and eosin staining for microscopic examination. Histopathological examination of salivary glands is a useful tool as a predictor of disease severity and lymphomagenesis in SS. Germinal centre (GC) formation is an early pathogenic symptom in the process of B cell lymphogenesis and MALT formation. GCs are detected immunohistochemistry for IgD/CD21 and IgD/CD38 or are based on haematoxylin and eosin plus staining for Bcl-6, as a marker of GC B cells [25]. The B-cell and FS proportion are good predictors of therapy effectiveness and clinical response to rituximab. Histopathology of salivary glands cannot be used for the assessment of salivary gland recovery because the inflammation in the glandular tissue causes irreversible damage in the form of fibrosis and loss of acinar cells leading to sustained decreased salivation [25].

The predominant histopathological findings of MD are dense lymphoplasmacytic infiltrates with storiform (whirl-shaped) fibrosis, obliterative phlebitis, and an abundance of IgG4-bearing plasma cells. More than 10 IgG4-positive cells per high-power field and a ratio of IgG4-positive cells to all IgG-bearing cells $>40-50 \%$ are diagnostic criteria of MD and all IgG4RD. The abundance of IgG4-positive plasma cells is a necessary but not sufficient criterion for the diagnosis of IgG4-RD [26]. The infiltrate primarily consists of mature plasma cells, macrophages, eosinophils, and dispersed $\mathrm{T}$ lymphocytes. The isolated elevated IgG4+ plasma cell count is not specific for the IgG4$\mathrm{RD}$ diagnosis because it can be observed in many cancers and infectious diseases. Severe fibrosis without cytologic atypia is an important symptom in differential diagnosis of potentially malignant lesions of salivary glands that may imitate IgG-RD. Obliterative phlebitis is the most specific histopathologic feature of IgG4-RD. According to current recommendations, the number of IgG4+ plasma cells in MD should be based on three measurements. For the core-needle biopsy specimen the minimal number of IgG4+ plasma cells is 10/HPF, and additionally one of the two histopathologic parameters should be observed, and in case of harvested salivary glands the cut-off is 100 IgG4+ plasma cells/HPF [7]. 


\section{Imaging modalities in the differentiative diagnosis of MD and SS}

In diagnosis of SS and MD radiographic examinations play an additional helpful role. They are specific neither for MD nor for SS. In the diagnostics of IgG4RD imaging methods play an important role, depending on lesion location for example positron emission tomography (PET), computed tomography (CT), and magnetic resonance imaging (MRI). These examinations are helpful in the selection of affected organs for biopsy [7]. The main tests used for differentiation of MD and SS are sonography, CT, MRI, and 2-[ $\left.{ }^{18} \mathrm{~F}\right]$-fluoro-2-deoxy-D-glucose positron emission tomography/ computed tomography (FDG-PET/CT). The nodal pattern of the submandibular glands on sonograms and the abnormal accumulation of 2-[ $\left[{ }^{18} \mathrm{~F}\right]$-fluoro-2-deoxyD-glucose $\left({ }^{18} \mathrm{~F}-\mathrm{FDG}\right)$ in the submandibular glands on FDG-PET/CT are very effective in diagnosing MD. On the other hand, effective findings regarding the diagnosing of SS are a salt-and-pepper appearance and multiple cystic areas in the parotid glands on MRI. Comparing all these methods' high sensitivity for both IgG4-DS and SS, and high specificity in addition to high accuracy, the most effective imaging modality is sonography [27]. In sonography, changes typical for MD mainly affect the submandibular glands, with normal appearance of parotid glands. Conversely, SS shows atrophic changes in both the parotid and submandibular glands. The nodal and reticular patterns with normal parenchyma surrounding the affected region in both submandibular glands are the main manifestations of MD in sonography. On the other hand, SS is characterised by multiple hypoechoic areas and hyperechoic lines and spots in the parotid glands. However, similar findings can be observed also in MD patients leading to misdiagnosis. In these cases, the differentiative factors are hypoechoic areas in the normal parotid parenchyma without a reduction in the echo intensity level and heterogeneity in MD [27]. Therefore, the combination of parotid and submandibular gland findings could lead to accurate diagnosis. In the Doppler modality, the nodal and reticular patterns of MD show high vascularity, while SS exhibits small dot-like vascularity in the parotid glands. MRI demonstrates only diffuse enlargement of the affected salivary glands without nodularity or focal lesion and homogenous enhancement [28]. On the other hand, a special image of SS in MRI is described as "salt and pepper" or "honeycomb", particularly on T2-weighted images with fat deposition [28]. CT findings in SS are nonspecific. The glands are usually enlarged, containing nodules and cystic areas with fat deposition [28]. Sialography can demonstrate abnormal ductal architecture with deficient secondary and tertiary ducts in MD but currently is replaced by sialoendoscopy [28]. Although, sialoendoscopy is not the recommended examination to assess salivary gland involvement in SS, it is very helpful to diagnose and recognise the ductal abnormalities accompanying SS. The presence of hyperaemia at the level of main and second-order salivary ducts and perivascular inflammation and congestion in sialoendoscopic visualisation demonstrate the initial phases of SS whereas the pale, little vascularised appearance of the ductal wall express more advanced phases of the disease when parenchymal tissue is repleased by fibrosis. Obstructive mucous plugs frequently observed in the ductal tree cause saliva stagnation and salivary gland inflammation, which are responsible for occasional swelling and pain [5]. There are no reports about utility of sialoendoscopy in patients affected by IgG4-related sialadenitis and MD.

\section{The role of salivary gland biopsy in the diagnosis of MD and SS}

Salivary gland biopsies are common and recommended methods of taking glandular tissue from affected salivary glands to confirm sialadenitis in both SS and MD. Histopathological changes of salivary glands in SS are equally distributed in both major and minor salivary glands. Therefore, our management is determined by the availability of salivary glands and surgical approach. LSG are easy accessible and can be harvested by simple surgical procedure. Labial salivary gland biopsy (LSGB) is reported as a method in SS diagnosis, and its score is included in the classification criteria of SS. The sensitivity and specificity of LSGB are reported at $86.7 \%$ and $97.4 \%$, respectively [29]. LSGB is a minimally invasive procedure performed under local anaesthesia. It is also a means of diagnosing other diseases, including amyloidosis, sarcoidosis, and lymphoma accompanying SS [30]. The main limitations of the assessment of FS in LSGB come from possible severe acinar atrophy, interstitial fibrosis, and fat cells in glandular specimens. Moreover, fibrosis, acinar atrophy and the amount of adipose tissue increase with age. There are a few potentially important points in taking LSGB. The tissue specimens should include a sufficient amount of salivary gland. The larger tissue specimens allow artefacts from atrophic and damaged cells to be overcome. On the other hand, a larger operative field increases the surgical risk of postoperative complications including lip numbness, postoperative inflammation or improper healing, local pain, swelling, external haematoma, formation of granulomas, internal scarring, and cheloid formation. Furthermore, the distribution of the inflammatory cells in the gland may be uneven. For reduction of misdiagnosis resulting from the single tissue section a recommended modification is a multi-section and taking LSG at different depths from the same incision [31-33]. Moreover, LSGB can be valuable in diagnosing B-cell mucosa-associated lymphoid tissue (MALT) lymphomas, which can accompany SS. $4 \%$ to $7 \%$ of 
patients with SS develop malignant B cell lymphoma, $48 \%$ to $75 \%$ of which are of the MALT type [26]. Furthermore, LSGB may be a very useful in the diagnosis of SS in children [34]. Unfortunately, LGB is not recommended for monitoring disease progression and treatment evaluation. The main alternative types of salivary gland biopsies in SS are parotid gland biopsy and sublingual gland biopsy. Parotid gland biopsy allows the clinician to monitor the disease progression and to assess the effect of an intervention treatment in SS. Parotid tissue can be harvested easily, repeated biopsies from the same parotid gland are possible, and the histopathologic results can be compared with other diagnostic results derived from the same gland, such as secretory function, sialographic appearance, and ultrasonography. Furthermore, parotid biopsy is better in the identification of lymphomas. The main possible complications of parotid gland biopsy are facial nerve damage, Frey's syndrome, and development of sialoceles and salivary fistulae. The sensitivity and specificity of parotid gland biopsy and LSGB are comparable, estimated to be $78 \%$ and $86 \%$, respectively [35]. The biopsy of salivary glands remains the main means of obtaining the representative tissue specimens for microscopic examination in MD and other IgG4-RD. However, there are different recommendations for the choice of suitable salivary glands in MD confirmation. The sensitivity, specificity, and accuracy of SMG biopsies have been reported as being $100.0 \%$. The same parameters in LSG biopsies have been reported at $69.2 \%, 100.0 \%$, and $71.4 \%$, respectively [36]. The most common type of biopsy in MD is submandibular gland (SMG) biopsy. It can be either excisional or incisional biopsy. Swelling of the SMG is the main recommendation for incisional biopsy. Incisional biopsy of the SMG is useful for diagnosing IgG4-DS, in addition to being a less invasive procedure than excisional biopsy under general anaesthesia. SMG biopsy in IgG4-RD specimens allows the detection of strong lymphocytic infiltration with hyperplastic germinal centres, mild destruction of the acini, and selective infiltration by IgG4-positive plasma cells with an IgG4positive plasma cells/IgG-positive plasma cells ratio $>0.4$. LSGB is a less invasive procedure and causes less severe complications. Although LSG specimens can show similar histological findings, specimens usually present only mild lymphocytic infiltration with an IgG4-positive plasma cells/IgG-positive plasma cells ratio $\leq 0.4$ and without germinal centres. Moreover, the biopsy of the minor salivary glands could be used as an alternative method of diagnosis of all IGg4-RD, not only MD, especially in patients for whom more invasive biopsy of target organs is difficult or impossible even if there are no signs of clinical abnormality [30]. Minor salivary gland biopsy such as LSG biopsy may sometimes be substituted when biopsy of the major salivary glands is difficult. The sensitivity of detection of IgG4+plasma cells in LSG specimens is relatively low $[37,38]$. The utility of the parotid gland in diagnosing IgG4-RD has not been reported so far. Comparative studies suggest that both procedures sublingual and parotid biopsy - retain diagnostic potential comparable to that of lip biopsy and may be associated with lower postoperative morbidity. Parotid biopsy can be recommended in patients who have a negative minor salivary gland biopsy result.

\section{Conclusions}

Suspicion of MD and SS requires a comprehensive thorough diagnostic process based on histopathological and serological examination. Radiological modalities are helpful for the exclusion other possible inflammatory and neoplastic processes.

\section{Conflict of interest}

The author declares no conflict of interest.

\section{References}

1. Himi T, Takano K, Yamamoto M, Naishiro Y, Takahashi H. A novel concept of Mikulicz's disease as IgG4-related disease. Auris Nasus Larynx 2012; 39: 9-17.

2. Umehara H, Okazaki K, Masaki Y, Kawano M, Yamamoto M, Saeki T, Matsui S, Yoshino T, Nakamura S, Kawa S, Hamano H, Kamisawa T, Shimosegawa T, Shimatsu A, Nakamura S, Ito T, Notohara K, Sumida T, Tanaka Y, Mimori T, Chiba T, Mishima M, Hibi T, Tsubouchi H, Inui K, Ohara H. Comprehensive diagnostic criteria for IgG4-related disease (IgG4-RD). Mod Rheumatol 2012; 22: 21-30.

3. Mulholland GB, Jeffery CC, Satija P, Côté DW. Immunoglobulin G4-related diseases in the head and neck: a systematic review. J Otolaryngol Head Neck Surg 2015; 44: 24.

4. Della-Torre E, Lanzillotta M, Doglioni C. Immunology of IgG4-related disease. Clin Exp Immunol 2015; 181: 191-206.

5. Gallo A, Martellucci S, Fusconi M, Pagliuca G, Greco A, De Virgilio A, De Vincentiis M. Sialendoscopic management of autoimmune sialadenitis: a review of literature. Acta Otorhinolaryngol Ital 2017; 37: 148-154

6. Rolla D, Bellino D, Peloso G, Pia Rastaldi M, Simonini P, Louis Ravetti J. The first case of IgG4-related disease in Italy. J Nephropathol 2013; 2: 144-149.

7. Sebastian A, Dionizy P, Wiland P. IgG4-related disease and the spectrum of mimics in rheumatology. Chronic autoimmune epithelitis. Sjögren's syndrome and other autoimmune diseases of the exocrine glands. In: Chronic Autoimmune Epithelitis. Sjögren's Syndrome and Other Autoimmune Disease of the Exocrine Glands. Maslinska M (ed.). IntechOpen, London 2019; 73-85.

8. Wu Y, Xu ZR, Zhou WJ, Yang YM. Immunoglobulin G4related disease with features of Mikulicz's disease and autoimmune pancreatitis which firstly presented as asymptomatic lymphadenopathy: a case report. Chin Med J 2015; 128: 706-707.

9. Ochoa ML, López BG, Cabello RR, Feregrino RR. IgG4-related multiorgan disease: report of the first autopsy case. BMJ Case Rep 2013; 2013: bcr2013009636. 
10. Khosroshani A, Carruthers MN, Stone JH, Shinagare S, Sainani N, Hasserjian RP, Deshpande V. Rethinking Ormond's disease: "idiopathic" retroperitoneal fibrosis in the era of IgG4-related disease. Medicine 2013; 92: 82-91.

11. Maslińska M. Introductory Chapter: Autoimmune Epithelitis-Discussion about Sjögren's Syndrome and Primary Biliary Cholangitis. In: Chronic Autoimmune Epithelitis. Sjögren's Syndrome and Other Autoimmune Disease of the Exocrine Glands. Maslinska M (ed.). IntechOpen, London 2019; 3-12.

12. Błochowiak KJ, Trzybulska D, Olewicz-Gawlik A, Sikora JJ, Nowak-Gabryel M, Kocięcki J, Witmanowski H, Sokalski J. Levels of EGF and VEGF in patients with primary and secondary Sjögren's syndrome. Adv Clin Exp Med 2018; 27: 455-461.

13. Błochowiak K, Olewicz-Gawlik A, Polańska A, NowakGabrel M, Kocięcki J, Witmanowski H, Sokalski J. Oral mucosal manifestations in primary and secondary Sjögren's syndrome and dry mouth syndrome. Adv Dermatol Allergol 2016; 33: 23-27.

14. Błochowiak KJ, Olewicz-Gawlik A, Trzybulska D, NowakGabryel M, Kocięcki J, Witmanowski H, Sokalski J. Serum ICAM-1, VCAM-1 and E-selectin levels in patients with primary and secondary Sjögren's syndrome. Adv Clin Exp Med 2017; 26: 835-842.

15. Olewicz-Gawlik A, Polańska A, Trzybulska D, NowakGabryel M, Błochowiak K, Kocięcki J, Sokalski J, Żaba R, Adamski Z, Dańczak-Pazdrowska A. Acta Dermatovenerol Croat 2018; 26: 153-156

16. Xu WL, Ling YC, Wang ZK, Deng F. Diagnostic performance of serum IgG4 level for IgG4-related disease: a meta-analysis. Sci Rep 2016; 6: 32035.

17. Yun J, Wienholt L, Adelstein S. Poor positive predictive value of serum immunoglobulin G4 concentrations in the diagnosis of immunoglobulin G4-related sclerosing disease. Asia Pac Allergy 2014; 4: 172-176.

18. Li S, Deng C, Chen J, Li F. Mikulicz's disease with immune thrombocytopenia: a new immunoglobulin G4-mediated disorder and literature review. Arch Rheumatol 2018; 34: 343-347.

19. Kim J, Sun D, Ozl R, Beck TG, Birnbaum J, Akpek EK, Baer A. A validated method of labial minor salivary gland biopsy for the diagnosis of Sjögren's syndrome. Laryngoscope 2016; 126: 2041-2046.

20. Shiboski CH, Shiboski SC, Seror R, Criswell LA, Labetoulle M, Lietman TM, Rasmussen A, Scofield H, Vitali C, Bowman SJ, Mariette X. International Sjögren's syndrome criteria working. Classification criteria for primary Sjögren's syndrome. A consensus and data-driven methodology involving three international patient cohorts. Ann Rheum Dis 2017; 76: 9-16.

21. Shiboski CH, Shiboski SC, Seror R. 2016 American College of Rheumatology/European League Against Rheumatism Classification Criteria for primary Sjögren's syndrome. Arthritis Rheumatol 2017; 69: 35-45.

22. Franceschini F, Cavazzana I, Andreoli L, Tincani A. The 2016 classification criteria for primary Sjogren's syndrome: what's new? BMC Medicine 2017; 15: 69.

23. Tarpley TM Jr, Anderson LG, White CL. Minor salivary gland involvement in Sjögren's syndrome. Oral Surg Oral Med Oral Pathol 1974; 37: 64-74.

24. Chisholm DM, Mason DK. Labial salivary gland biopsy in Sjögren's disease. J Clin Pathol 1968; 21: 656-660.

25. Kroese F, Haacke E, Bombardieri M. The role of salivary gland histopathology in primary Sjögren's syndrome: promises and pitfalls. Clin Exp Rheumatol 2018; 112: 222-233.
26. Błochowiak K, Sokalski J. Labial salivary gland biopsy in the diagnosis of Sjögren's syndrome. Eur J Clin Exp Med 2019; 17: 162-168.

27. Shimizu M, Okamura K, Kise Y, Takeshita Y, Furuhashi H, Weerawanich W, Moriyama M, Ohyama Y, Furukawa S, Nakamura S, Yoshiura K. Effectiveness of imaging modalities for screening IgG4-related dacryoadenitis and sialadenitis (Mikulicz's disease) and for differentiating it from Sjögren's syndrome (SS), with an emphasis on sonography. Arthritis Res Ther 2015; 17: 223.

28. Rao D, Natter P, Fernandes R, Wang ZB, Sandhu SJS. A case report of Mikulicz syndrome. J Radiol Case Rep 2017; 11: 1-7.

29. Giovelli RA, Santos MCS, Serrano E, Valim V. Clinical characteristics and biopsy accuracy in suspected cases of Sjögren's syndrome referred to labial salivary gland biopsy. BMC Musculoskel Disord 2015; 16: 30.

30. Doe K, Nozawa K, Okada T, Tada K, Yamaji K, Tamura N, Takasaki Y. Usefulness of minor salivary gland biopsy in the diagnosis of IgG4-related disease: a case report. Int J Clin Exp Pathol 2014; 7: 2673-2677.

31. Delli K, Vissink A, Spijkervet FKL. Salivary gland biopsy for Sjögren's syndrome. Oral Maxillofac Surg Clin North Am 2014; 26: 23-33.

32. Sarioğlu S, KüÇük Ǔ, Cetin P, Sari I, Bǔrlǐk AM. Minor salivary gland evaluation: Sjögren's syndrome. Turk J Med Sci 2016; 46: 63-65.

33. Varela-Centelles P, Sanchez-Sanchez M, Seoane J. Lip biopsy for the diagnosis of Sjögren's syndrome: beware of the punch. Int J Oral Maxillofac Surg 2014; 43: 127-130.

34. Yokogawa N, Lieberman SM, Alawi F, Bout-Tabaku S, Guttenberg M, Sherry DD, Vivino FB. Comparison of labial minor salivary gland biopsies from childhood Sjögren syndrome and age-matched controls. J Rheumatol 2014; 41: 1178-1182.

35. Pijpe J, Kalk WW, van der Wal JE, Vissink A, Kluin PM, Roodenburg JL, Bootsma H, Kallenberg CG, Spijkervet FK. Parotid gland biopsy compared with labial biopsy in the diagnosis of patients with primary Sjögren's syndrome. Rheumatology 2007; 46: 335-341.

36. Moriyama M, Furukawa S, Kawano S, Goto Y, Kiyoshima T, Tanaka A, Maehara T, Hayashida JN, Ohta M, Nakamura S. The diagnostic utility of biopsies from the submandibular and labial salivary glands in IgG4-related dacryoadenitis and sialoadenitis, so-called Mikulicz's disease. Int J Oral Maxillofac Surg 2014; 43: 1276-1281.

37. Masaki Y, Kurose N, Umehara H. IgG4-related disease: a novel lymphoproliferative disorder discovered and established in Japan in the 21st century. J Clin Exp Hematop 2011; 51: 13-20.

38. Kamiński B, Guzera Z. The unknown face of labial salivary glands. Labial salivary gland biopsy as a diagnostic tool. Medical Studies 2019; 35: 172-179.

\section{Address for correspondence:}

Bartłomiej Kamiński MD, PhD

Otolaryngology Ward

Maria Sklodowska-Curie District Hospital

ul. Szpitalna S1, 26-110 Skarżysko-Kamienna, Poland

Phone: +48 602491654

E-mail: bartl.kaminski@gmail.com 